\title{
Music processing similarities between sleeping newborns and alert adults: cause for celebration or concern?
}

\author{
Sandra E. Trehub* \\ Department of Psychology, University of Toronto Mississauga, Mississauga, ON, Canada \\ ${ }^{*}$ Correspondence: sandra.trehub@utoronto.ca \\ Edited by: \\ Josef P. Rauschecker, Georgetown University School of Medicine, USA \\ Reviewed by: \\ Isabelle Peretz, Université de Montréal, Canada
}

Keywords: music perception, newborns, interpretations, adult comparisons, infants

\section{A commentary on}

Newborn infants' auditory system is sensitive to Western chord categories

by Virtala, P., Houtilainen, M., Partanen, E., Fellman, V., and Tervaniemi, M. (2013). Front. Psychol. 4:492. doi: 10.3389/fpsyg. 2013.00492

The proliferation of newborn "musical" abilities is accelerating with the ever-increasing use of neurophysiological methods with sleeping newborns. Newborn abilities that have surfaced in recent years include beat detection (Winkler et al., 2009), representation of pitch independent of timbre (Háden et al., 2009), representation of pitch intervals independent of absolute pitch (Stefanics et al., 2009), detection of changes in tonal key (Perani et al., 2010), and lateralized responses to speech and music (Kotilahti et al., 2010; Perani et al., 2010). Virtala et al. (2013) add to this body of work with their report of newborns' sensitivity to major vs. minor chords and consonant vs. dissonant chords.

Unquestionably, the newborn brain registers the aforementioned differences in some manner, but does such registration enrich our knowledge of music processing and its development? The answer is affirmative but with important reservations. Newborns in Virtala et al. (2013) responded to chords on the basis of relative rather than absolute pitch cues, confirming previous neurophysiological and behavioral evidence of relational processing in newborns (Stefanics et al., 2009) and older infants (e.g., Plantinga and Trainor, 2005).

What about the reservations? The authors' interpretation of newborns' neural responses to the major/minor distinction raises serious concerns. They argue that newborn responses were based on major or minor chord quality rather than mere acoustic differences. Infants could have responded to simple differences in interval size, as the authors acknowledge, because the lower interval of the minor chord (minor third, 3 semitones) is smaller than that of the major chord (major third, 4 semitones). If newborns really differentiate major from minor chord quality, as the authors contend, then why do preschoolers (Costa-Giomi, 1996) and musically untrained 13-yearolds (Virtala et al., 2012) fail to do so? The authors suggest that early sensitivity to the major/minor distinction could disappear in the absence of musical training, but it is unclear what would prompt such a disappearance. Loss of sensitivity to specific phonetic distinctions has been reported for distinctions that are irrelevant to the language being learned (Werker and Tees, 2005). The major/minor distinction, although not universal, is surely relevant to Western music and to the young children who fail to notice it.

The authors' interpretation of newborns' responsiveness to the consonance/dissonance distinction poses further problems. They suggest that sensitivity to this distinction can be regarded as a biological predisposition for musical skills. As with the major/minor distinction, newborns may have responded on the basis of the smaller lower interval (minor seconds or 2 semitones) in the dissonant chords than in the consonant chords (major thirds or 4 semitones). Sensitivity to the consonance/dissonance distinction has been reported in other species (e.g., Hulse et al., 1995), but no one is suggesting that birds have biological predispositions for music. In this instance, at least, what's good for the birds should be good for babies.

The present investigators are not alone in their generous interpretation of the infant findings. For example, newborns' apparent sensitivity to musical key (Perani et al., 2010) is out of line with children's insensitivity to key structure until 4 or 5 years of age (Corrigall and Trainor, 2010). Moreover, newborns' reported ability to process pitch independent of timbre (Stefanics et al., 2009) is at odds with adults' difficulty comparing pitches in the context of contrasting timbre (Borchert et al., 2011). By contrast, reports of beat detection in newborns (Winkler et al., 2009) are consistent with skills that infants display some months later (with different methods), for example, rhythm perception influenced by rhythmic movement (Phillips-Silver and Trainor, 2005) and preferences for native over nonnative musical meters (Soley and Hannon, 2010).

It is understandable that parents often provide very rich interpretations of their infants' and young children's abilities. There is less justification for comparably rich interpretations from scholars who study music perception in sleeping newborns. As scholars, we must remain on guard against anthropomorphism and ethnocentrism. We must be equally vigilant about adultomorphism.

\section{REFERENCES}

Borchert, E. M. O., Micheyl, C., and Oxenham, A. J. (2011). Perceptual grouping affects pitch judgments across time and frequency. J. Exp. Psychol. Hum. 37, 257-269. doi: 10.1037/a0020670

Corrigall, K. A., and Trainor, L. J. (2010). Musical enculturation by preschool children: acquisition of 
key and harmonic knowledge. Music Percept. 28, 195-200. doi: 10.1525/mp.2010.28.2.195

Costa-Giomi, E. (1996). Mode discrimination abilities of pre-school children. Psychol. Music 24, 184-198. doi: $10.1177 / 0305735696242010$

Háden, G. P., Stefanics, G., Vestergaard, M. D., Denham, S. L., Sziller, I., and Winkler, I. (2009). Timbre-independent extraction of pitch in newborn infants. Psychophysiology 46, 69-74. doi: 10.1111/j.1469-8986.2008.00749.x

Hulse, S. H., Bernard, D. J., and Braaten, R. F (1995). Auditory discrimination of chord-based spectral structures by European starlings (Sturnus vulgaris). J. Exp. Psychol. Gen. 124, 409-423. doi: 10.1037/0096-3445.124.4.409

Kotilahti, K., Nissilä, I., Näsi, T., Lipiainen, L., Niponen, T., Meriläinen, P., et al. (2010). Hemodynamic responses to speech and music in newborn infants. Hum. Brain Mapp. 31, 595-603.

Perani, D., Saccuman, M. C., Scifo, P., Spada, D., Andreolli, G., Rovelli, R., et al. (2010). Functional specializations for music processing in the human newborn brain. Proc. Natl. Acad. Sci. U.S.A. 107, 4758-4763. doi: 10.1073/pnas.0909074107

Phillips-Silver, J., and Trainor, L. J. (2005). Feeling the beat: movement influences infant rhythm perception. Science 308, 1430. doi: 10.1126/science.1110922

Plantinga, J., and Trainor, L. J. (2005). Memory for melody: infants use a relative pitch code. Cognition 98, 1-11. doi: 10.1016/j.cognition.2004.09.008

Soley, G., and Hannon, E. E. (2010). Infants prefer the musical meter of their own culture: a cross-cultural comparison. Dev. Psychol. 46, 286-292. doi: 10.1037/a0017555

Stefanics, G., Háden, G. P., Sziller, I., Balázs, L., Beke, A., and Winkler, I. (2009). Newborn infants process pitch intervals. Clin. Neurophysiol. 120, 304-308. doi: 10.1016/j.clinph. 2008.11.020

Virtala, P., Huotilainen, M., Partanen, E., Fellman, V., and Tervaniemi, M. (2013). Newborn infants' auditory system is sensitive to Western chord categories. Front. Psychol. 4:492. doi: 10.3389/fpsyg. 2013.00492

Virtala, P., Houtilainen, M., Putkinen, V., Makkonen, T., and Tervaniemi, M. (2012). Musical training facilitates the neural discrimination of major versus minor chords in 13-year-old children. Psychophysiology 49, 1125-1132. doi: 10.1111/j.1469-8986.2012.01386.x

Werker, J. F., and Tees, R. C. (2005). Speech perception as a window for understanding plasticity and commitment in language systems of the brain. Dev. Psychobiol. 46, 233-251. doi: 10.1002/ dev. 20060

Winkler, I., Háden, G. P., Ladinig, O., Sziller, I., and Honing, H. (2009). Newborn infants detect the beat in music. Proc. Natl. Acad. Sci. U.S.A. 106, 2468-2471. doi: 10.1073/pnas.0809035106

Received: 24 July 2013; accepted: 29 August 2013; published online: 19 September 2013.

Citation: Trehub SE (2013) Music processing similarities between sleeping newborns and alert adults: cause for celebration or concern? Front. Psychol. 4:644. doi: 10.3389/fpsyg.2013.00644

This article was submitted to Auditory Cognitive Neuroscience, a section of the journal Frontiers in Psychology.

Copyright (c) 2013 Trehub. This is an open-access article distributed under the terms of the Creative Commons Attribution License (CCBY). The use, distribution or reproduction in other forums is permitted, provided the original author(s) or licensor are credited and that the original publication in this journal is cited, in accordance with accepted academic practice. No use, distribution or reproduction is permitted which does not comply with these terms. 